\title{
The Role of Digital Technology in Responding to COVID-19 Pandemic: Saudi Arabia's Experience
}

\author{
Anas Khan $\mathbb{D}^{1,2}$ \\ Ahmed Alahmari (iD) ${ }^{2}$ \\ Yasir Almuzaini $\mathbb{1}^{2}$ \\ Nada Alturki ${ }^{2}$ \\ Alhanouf Aburas $\mathbb{D}^{3}$ \\ Fahad A Alamri $\mathbb{1}^{2}$ \\ Mohammed Albagami (D) ${ }^{4}$ \\ Mashael Alzaid $\mathbb{D}^{4}$ \\ Turki Alharbi $\mathbb{D}^{4}$ \\ Rahaf Alomar (D) ${ }^{4}$ \\ Muath Abu Tayli ${ }^{4}$ \\ Abdullah M Assiri (D) \\ Hani A Jokhdar $\mathbb{D}^{6}$ \\ 'Department of Emergency Medicine, \\ College of Medicine, King Saud \\ University, Riyadh, Saudi Arabia; ${ }^{2} \mathrm{Global}$ \\ Center of Mass Gatherings Medicine, \\ Ministry of Health, Riyadh, Saudi Arabia; \\ ${ }^{3}$ Health Sciences Department, College of \\ Health and Rehabilitation Sciences, \\ Princess Nourah Bint Abdulrahman \\ University, Riyadh, Saudi Arabia; ${ }^{4}$ Saudi \\ Data and Artificial Intelligence Authority, \\ Riyadh, Saudi Arabia; ${ }^{5}$ Ministry of Health, \\ Riyadh, Saudi Arabia; ${ }^{6}$ Deputyship of \\ Public Health, Ministry of Health, Riyadh, \\ Saudi Arabia
}

Correspondence: Alhanouf Aburas Health Sciences Department, College of Health and Rehabilitation Sciences, Princess Nourah Bint Abdulrahman University, Riyadh, Saudi Arabia Email Alhanoufaburas@gmail.com
Introduction: The novel coronavirus (COVID-19) is caused by severe acute respiratory syndrome coronavirus 2 (SARS-CoV-2), a single-chain ribonucleic acid (RNA) virus. As of March 25, 2021, the total number of positive cases and fatalities in the Kingdom of Saudi Arabia (KSA) had reached 386,300 and 6624 , respectively, with a case fatality rate of $1.71 \%$. The KSA was among the leading nations to heed the advice of WHO officials and put strict precautionary and preventive measures in place to curb the early spread of COVID-19 before it was declared a global pandemic.

Methodology: This was an uncontrolled before-after study following a mixed-method approach for data collection. National and regional data were extracted from the Health Electronic Surveillance Network (HESN), a centralized public health collection system for quantitative and statistical data. Quantitative and qualitative methods have been utilized in studying data derived from tech media.

Results: The Saudi authorities utilized different technological tools to aid in managing and combating the COVID-19 pandemic. In the case of Al Madinah Al Mounawarah, after the implementation of several technologies, the most important being Tawakkalna, the number of active daily cases decreased by $61 \%$.

Conclusion: The use of the Tawakkalna application was proven to be a successful method in fighting the COVID-19 pandemic in the KSA. This vital and essential experience warrants the use of different digital technology that offers a personalized profile displaying the person's status (affected, vaccinated, or no history of infection). This application played and will continue to play a crucial and effective role in pandemic containment in Saudi Arabia.

Keywords: digital technology, risk management, Saudi Arabia, applications

\section{Introduction}

The novel coronavirus (COVID-19) caused by the severe acute respiratory syndrome coronavirus 2 (SARS-CoV-2) a single-chain ribonucleic acid (RNA) virus. ${ }^{1}$ Established evidence on the transmission of RNA viruses demonstrates person-toperson transmission through respiratory droplets, both airborne and on fomites. Common symptoms associated with COVID-19 are pyrexia, dyspnea, and dry cough. $^{2,3}$ The global spread of COVID-19 recorded a total of 117,455,738 positive cases and 2,605,472 fatalities, with a global case fatality rate (CFR) of $2.21 \%$ as of March 25, 2021. Data gathered to date confirmed that COVID-19 has 2.5 times the transmission rate of the influenza virus. ${ }^{4-6}$ This discovery further supported the global consensus for mask use and physical distancing as valid protective measures. ${ }^{7}$ The rapid viral spread of the virus and the state of lockdown contributed to the bleak 
economic outlook and dire need for increased healthcare capacities in the countries most affected by the virus. ${ }^{8}$ As of March 8, 2021, the total number of positive cases and fatalities in the Kingdom of Saudi Arabia (KSA) had reached 386,300 and 6624 , respectively, with a CFR of $1.71 \%$. The KSA was among the first nations to apply the precautionary and preventive measures advised by WHO officials to curb the early spread of COVID-19 before it was declared a global pandemic. ${ }^{9}$ Furthermore, the KSA utilized its position and influence to collaborate with stakeholders and neighboring nations in adopting similar measures, placing emphasis on unity in the global fight against the pandemic. This unified front was showcased in 2020, when the KSA took the lead in planning and hosting the G20 summit-making one of the main topics of discussion the ways in which the pandemic can be fought on a regional and global scale. On a local level, one of the key initiatives included linking all major local institutions by creating a high-level committee consisting of national leaders, restricting local and international travel, quarantining returning travelers from highly impacted countries, ${ }^{10}$ raising healthcare capacity and allotting facilities for COVID-19 treatment, banning mass gatherings, enforcing national lockdowns, and promoting campaigns aimed at raising public awareness and educating the public on nonpharmaceutical interventions like mask wearing in public places, social distancing, and frequent use of hand sanitizers. ${ }^{11}$ In line with a WHO-published manual entitled
"Operational Planning Guidelines to Support Country Preparedness and Response," which detailed the best practices in fighting the pandemic - the Kingdom established and enforced the national eight pillars of response, as shown in Figure 1. The use of digital technology in the eight pillars of response is vital for the function and success of each respective area of preparedness and response. ${ }^{13-15}$ These technologies have been adapted worldwide to perform multiple tasks related to the pandemic, including prevention and such surveillance as contact tracing. ${ }^{12}$ Moreover, these different technologies had several benefits, including 35 separate beneficial effects that improved patients' outcomes and decreased the impact of the outbreak. ${ }^{13}$ To measure the success of IT use in the KSA, we analyzed the experiences of other nations that followed a similar strategy. The results were used as an external benchmark for those of the KSA.

In this study, an attempt was made to explore how the KSA fully utilized advanced digital technology during the pandemic, especially its use of the Tawakkalna application, an epidemiological tool evaluating contact tracing, infection control and prevention, and public health management of COVID-19 cases during the phase of containing the increase of new cases in Al Madinah Al Mounawarah.

Commonly simplified as Madinah or Medina, Al Madinah Al Mounawarah is one of the three holiest cities in the religion of Islam and the capital of the Madinah Province of Saudi Arabia.

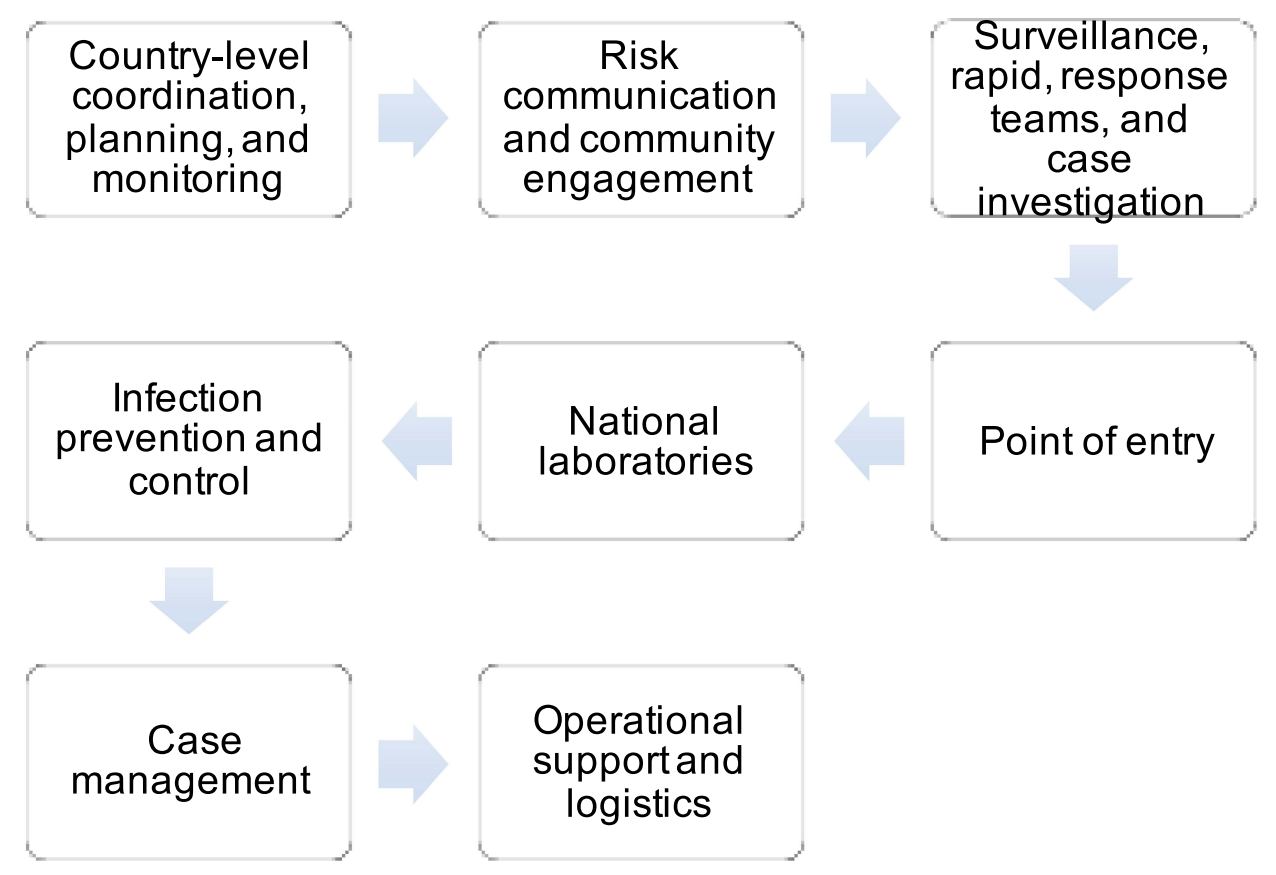

Figure I The eight pillars of response "COVID-19 Strategic Preparedness \& Response Plan". 
This study will also showcase how the KSA fully embraced technological advancement by fully digitizing several measures for maximum accuracy and capacity. Furthermore, we will examine the efficiency of these methods and whether they played a role in making the management of COVID-19 more efficient, systematic, and structured. Sharing the challenges faced and the overall results may help other countries take advantage of the KSA's experience in utilizing this technology.

\section{Methodology}

This is an uncontrolled before-after study following a mixed-method approach for data collection. National and regional data were extracted from the Health Electronic Surveillance Network (HESN), a centralized public health data collection system part of the Ministry of Health $(\mathrm{MoH})$ and openly accessible to relevant departments. Qualitative data were collected through a broad approach of assessing official reports and summaries released by governmental bodies in both Arabic and English language's, careful examination of committee meeting reports and consensus recommendations, and a comprehensive literature analysis. Quantitative and qualitative methods have been utilized in studying data derived from tech media. We further analyzed the effects of the use of those tech media, such as web platforms and cellphone applications, in decreasing the spread of recorded infections in KSA. One of the main IT programs used by the KSA was the Tawakkalna application. Its recorded use in high-risk regions from the period of September 2020 to December 2020 was closely examined -for all active cases- along with the epidemiological changes before and after its launch. This paper is part of a broader project aimed to detail KSA's COVID-19 experience in regard to preventive measures and guidelines to combat the spread which has been previously approved by the Saudi Ministry of Health Central Institutional Board.

\section{Results}

Upon detecting the first COVID-19 case in March 2020, the KSA chose to follow a precautionary approach in facing the initial stage of the epidemic by taking into consideration the full implementation of all global public health recommendations for containment and mitigation strategies. The large-scale application of various intervention measures was achieved by developing nine applications and leveraging eight other digital technologies with the aim of establishing a sustainable and effective method
Table I The Various Digital Technology Used During COVID-19 Pandemic Response in KSA

\begin{tabular}{|l|l|l|}
\hline Name of Digital Technology & Developed & Leveraged \\
\hline Tahoub & $\sqrt{ }$ & $\sqrt{ }$ \\
Anat & $\sqrt{ }$ & $\sqrt{ }$ \\
Tawakkalna & & $\sqrt{ }$ \\
Wasfaty & & $\sqrt{ }$ \\
Asefni & & $\sqrt{ }$ \\
Mawid & $\sqrt{ }$ & \\
Ihalati & & $\sqrt{ }$ \\
Tabaud & $\sqrt{ }$ \\
Sehaty & $\sqrt{ }$ & \\
HESN & $\sqrt{ }$ \\
Takasi & $\sqrt{ }$ \\
HEWS & $\sqrt{ }$ \\
Eatmarna & $\sqrt{ }$ & \\
Eshara & & $\sqrt{ }$ \\
Web Platforms (https://covid I9aware & \\
ness.sa/en/home-page) & & \\
Twitter and other Social Media & & \\
Telatforms & & \\
\hline
\end{tabular}

for reducing the risk of transmission and reaching optimal intervention and prevention strategies, some of these applications were developed and others were leveraged, as shown in Table 1 .

\section{Risk Communication}

\section{Twitter and Other Social Media Platforms}

Twitter, the most widely used social media network, followed by WhatsApp and other social media platforms used by the public, ${ }^{14}$ was utilized by government officials and concerned institutions to reach the populace by broadcasting daily updates on confirmed cases, fatalities, and recoveries. Social media were also used to spread health awareness, educational messages, and visual infographics to keep the public informed on current precautionary measures and encourage individuals to follow government instructions. ${ }^{15}$

\section{Call 937}

Since the first COVID-19 case was detected on March 3, the MoH allocated a national toll free number available 24 hours a day to answer any inquiries regarding the disease and provide consistent instructions on how to address their concerns or gain an understanding of various preventative measures put in place by the government for the disease. ${ }^{16}$ 
Web Platforms (https://covid I 9awareness.sa/en/ home-Page)

The $\mathrm{MoH}$ created a web platform as a centralized location to dispense all COVID-19 information, announce the latest health measures taken by the government, showcase ways for people to protect themselves from infection, and guide those with suspected infections on the proper steps to take in addressing their concerns.

\section{Development of Public Mobile}

\section{Applications}

\section{Tetamman}

This application was intended to provide updates and follow-ups for patients seeking medical attention beyond health facilities, such as low-risk isolated patients. Users may also initiate the first step by reporting their symptoms to seek appropriate interventions. It additionally incorporates well-being checks, provides detailed medical instructions, and operates as a national testing platform for the public to book COVID-19 tests and view the results. ${ }^{17}$

\section{Eshara}

Eshara is an application mainly used by special-needs patients as a tool for communicating with medical staff in health facilities. Hearing-impaired and mute patients may seek assistance from this application by directly being connected to sign language experts who can professionally relay their concerns to healthcare workers in an efficient, accurate, and orderly manner. ${ }^{18}$

\section{Eatmarna}

This application was created by the Ministry of Hajj \& Umrah to facilitate, track, and approve permits to visit the Two Holy Mosques for religious purposes. This enables officials to limit the number of visitors, consult with public health authorities on appropriate and safe capacity levels, and fully educate those approved on protection and precautionary measures. ${ }^{19}$

\section{Surveillance}

\section{Health Early Warning System (HEWS)}

HEWS is based on syndromic and event-based surveillance, which rapidly detects health threats, monitors ongoing health events (situational awareness), and tracks public health risks to ensure the health and well-being of the population. The platform plays an essential role in monitoring and mitigating risks and avoidable morbidity and mortality. It operates by integrating multiple data sources into a single platform for maximum efficiency and accuracy. ${ }^{20}$

\section{Contact Tracing Takasi}

Takasi ("Track") is a centralized tool used by concerned healthcare professionals to register COVID-19 data in a consolidated database for testing, public health surveillance, and case investigation and contact tracing. It allows data extraction and visualization of cases. ${ }^{21}$

\section{Health Electronic Surveillance Network (HESN)}

HESN is an integrated public health information system and acts as a one-stop platform that encompasses all aspects of public health, enabling public health professionals to better detect, respond, prevent, and control diseases and injuries in addition to monitoring the population's health status, thus empowering decisionmakers to lead and manage more effectively by providing timely, useful, high-quality data. ${ }^{22}$

\section{Quarantine and Self-Isolation}

Tabaud

This app uses anonymous spatial identification of proximity using low-power Bluetooth technology and three main services for users. It notifies people if they have had contact with a confirmed COVID-19 case, assists them in sending their health forms to the $\mathrm{MoH}$ for follow up and update, and enables those confirmed COVID-19 cases to voluntarily share their test results with people with whom they had contact during the past 14 days. ${ }^{23}$

\section{Clinical Management Ihalati Program}

The aim of this app is to raise efficiency and increase the capacity of medical transfers by limiting the number of steps, decreasing needed staff, and eliminating all paper transfers by incorporating a fully digital centralized system. This system optimizes the experience for both patients and healthcare workers and increases the quality of the healthcare provided. ${ }^{16}$

\section{Mawid}

The Mawid application is a central appointment system used by patients to manage their appointments and referrals to primary healthcare centers. ${ }^{24}$

\section{Remote Public Healthcare with Telemedicine Service} Remote telemedicine is an initiative that was launched by both private and public healthcare institutions and endorsed by the $\mathrm{MoH}$ to eliminate unnecessary physical visits, making it safer for patients and health practitioners 
to provide medical advice with little to no risk. Remote telemedicine further operates as a safe, interactive, inclusive system for those with disabilities and special needs. ${ }^{25}$

\section{Asefni}

Asefni ("Save me!") is an application created by the Saudi Red Crescent Authority (SRCA) for emergency services. The ease of submission and accurate GPS tracking enables emergency service personnel to reach concerned individuals instantly and efficiently with minimal downtime. Alternative user for people with special needs is also available through voice-over text messaging. ${ }^{26}$

\section{Wasfaty}

Available in both smartphone applications and web platforms, Wasfaty ("My Prescription") operates as a medium between healthcare centers, patients, and pharmacies by automating pharmaceutical prescriptions through its platform and directing patients to the nearest pharmacy with available stock. ${ }^{27}$

\section{Anat}

Used in conjunction with other $\mathrm{MoH}$ applications, Anat (https://anat.sa/) is a platform used by healthcare providers to issue e-prescriptions, register health practitioners, connect practitioners to available continuing education courses and health events in line with their specialty, and facilitate telemedicine through e-consultations.

\section{Sehaty}

Sehaty ("My Health") is a one-stop service equipped for smartphone and web platform use. Through this service, patients may access all their health information and view their health profile. Users may also book appointments for COVID-19 tests and vaccinations; view and be notified of their test results, medication list, immunizations, and appointments; and be issued reports by healthcare providers. $^{28}$

\section{Tahoub}

This program is connected to the Command and Control Center of the $\mathrm{MoH}$ to track the epidemiological situation and face public health threats. The program also heads the national surveillance system based on national and global standards. $^{29}$

\section{Tawakkalna}

Tawakkalna is one of the main applications used to detect, trace, and avoid risks of infection. Users have personalized profiles Users have personalized health profiles detailing the health status and history of people they encounter through direct and in person contact. This information includes current and past infection status as shown in Figure 2 which displays a dummy account for descriptive purposes. This feature is achieved by taking an active stance on early warning and detection and cautioning individuals from venturing into high-risk areas where a high number of infections have been recorded and warning users to get tested if they

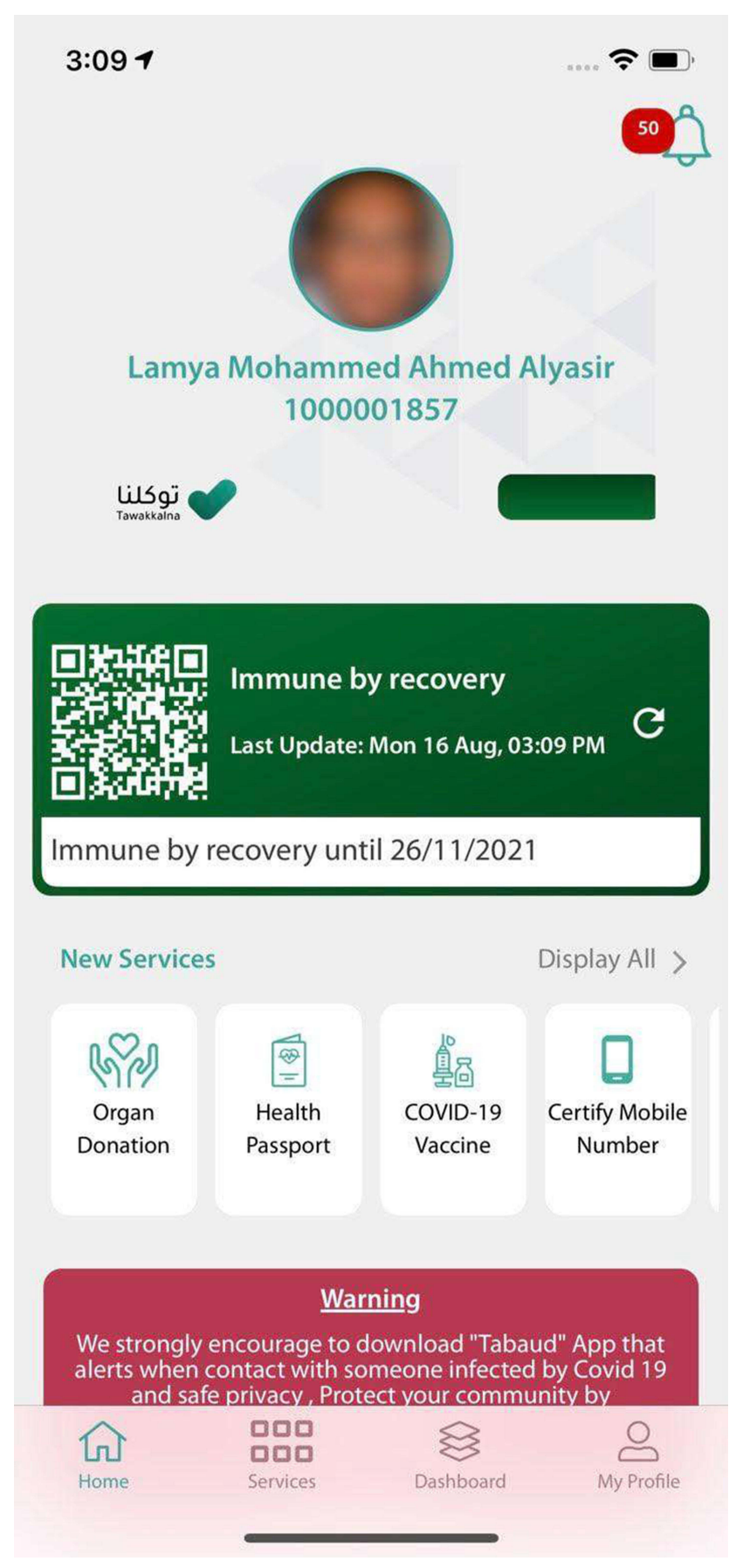

Figure 2 Tawakkalna application's home page. 
come into contact with at-risk individuals. Additionally, the application offers extensive crowd control services and is integrated with $\mathrm{MoH}$ test scheduling, which can be viewed on the user's health profile, showing whether the user is negative, positive, or awaiting results. This is further linked to the national vaccination registry and used to generate reports. Tawakkalna was also used during national and regional lockdowns for individuals to request electronic movement permits in cases of emergency. Ultimately, the apps were developed to perform a more advanced range of services, including Umrah Hajj and gatherings permits, deeds previews, Ministry of Justice appointment health passports, and medical conditions cards. ${ }^{30}$

\section{Al Madinah Al Mounawarah as a Case Study on the Effectiveness of the Full Implementation of Digital Technology}

The outbreak trends in Al Madinah Al Mounawarah were analyzed, and the epidemiological situation was examined by extracting a dataset for patients from HESN and highlighting demographic characteristics and epidemiological trends before technological tools, especially Tawakkalna, were implemented. The parallel change in the epidemiological situation in Al Madinah Al Mounawarah is featured in Figure 3. The daily diagnosed cases before implementation are shown in Figure 4. The cases after implementation are shown in Figure 5.

\section{Demographics}

As shown in Table 2, among the 10,129 positive COVID-19 cases, half (50\%) were young and ranged from 21 to 40 years old. Over half of the cases $(57 \%)$ were males. The majority of the cases were Saudis (71\%), most of the cases were employed (63\%), and the most represented source of infection was within households $(45 \%)$, mainly from first-degree family members $(37 \%)$.

\section{Intervention}

As a result of the increasing number of reported cases in Al Madinah Al Mounawarah and the subsequent challenge the healthcare sector had to face in managing hospital bed surge capacity, the $\mathrm{MoH}$ took several firm steps to curb the spread of the outbreak. Following an extensive situation analysis and review of epidemiological factors, causes, and sources of infections, all necessary strategic measures were implemented. The use of technology contributed to the Kingdom's response, as explained here.

The three principal applications, Tawakkalna, Tabaud, and Takasi, were connected together, Tawakkalna was made the main platform, which comprehensively incorporated all precautionary and preventive measures. Furthermore, all governmental, commercial, and hospitality venues - and places of worship, especially the Prophet Mohammed (PBUH) Mosque - were obligated by law to forbid within their

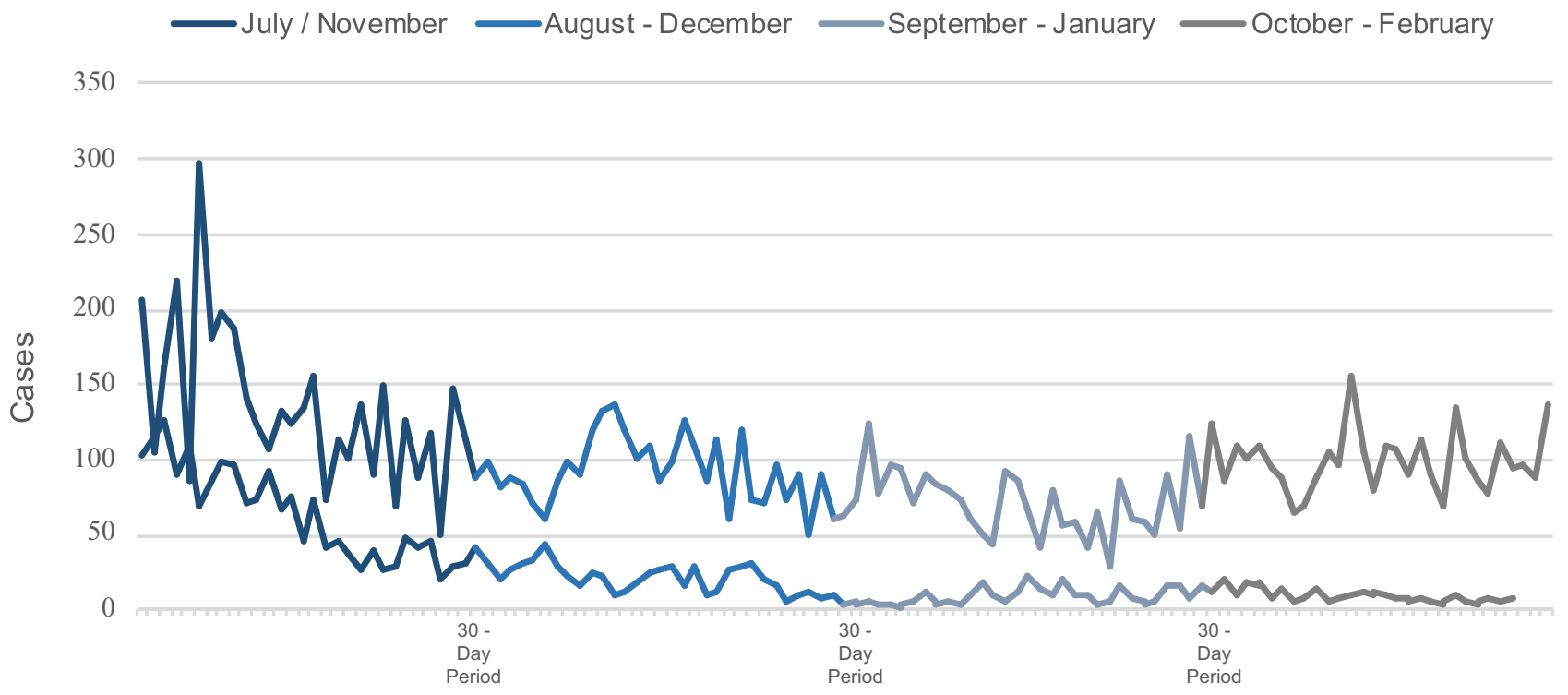

Figure 3 Parallel Change in the Epidemiological Situation of AI Madinah AI Mounawarah; four months within an eight-month period (Ist of July - 30th of February 202I). 


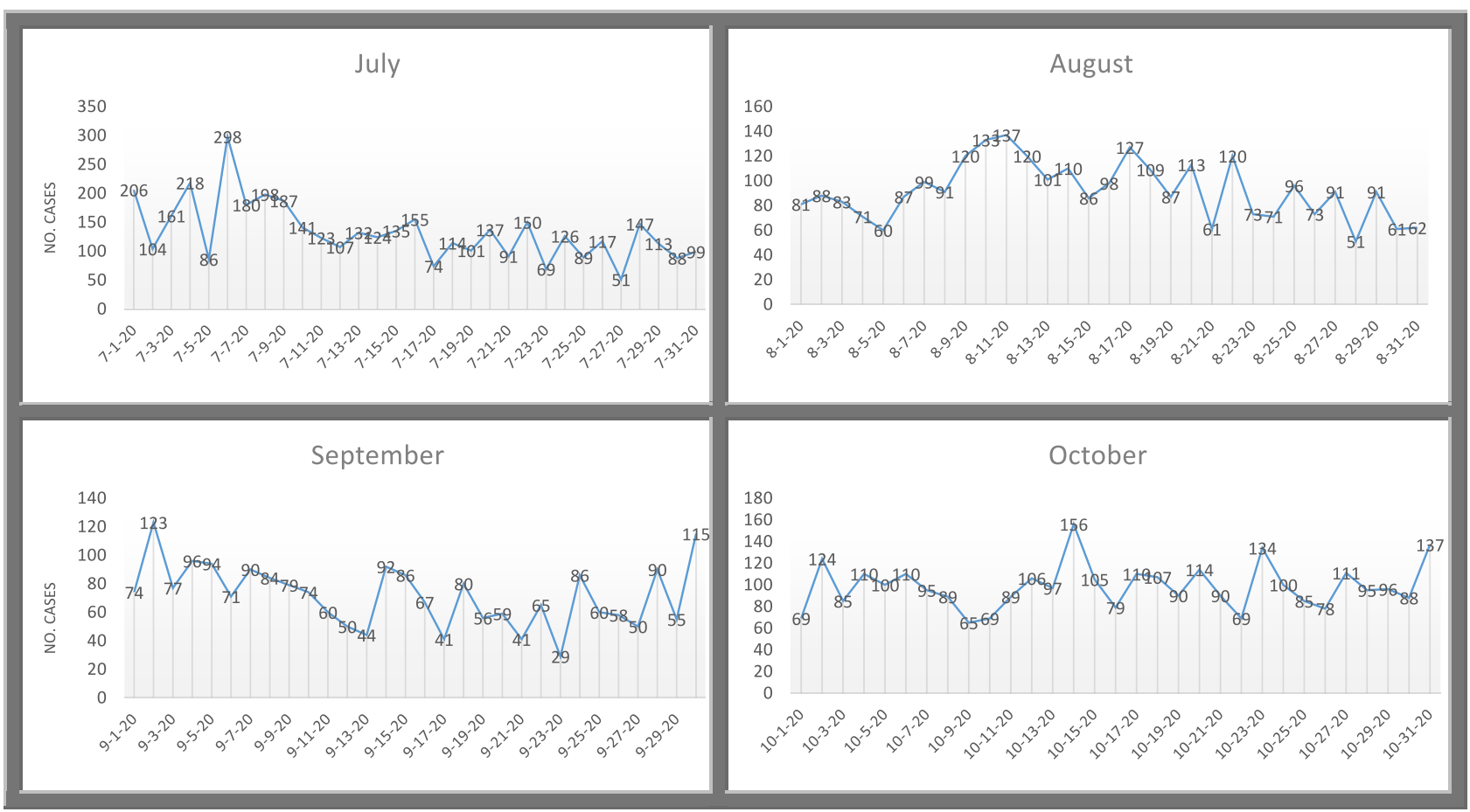

Figure 4 Epidemiological Situation of Al Madinah AI Mounawarah (Ist of July - 3 I of October 2020).

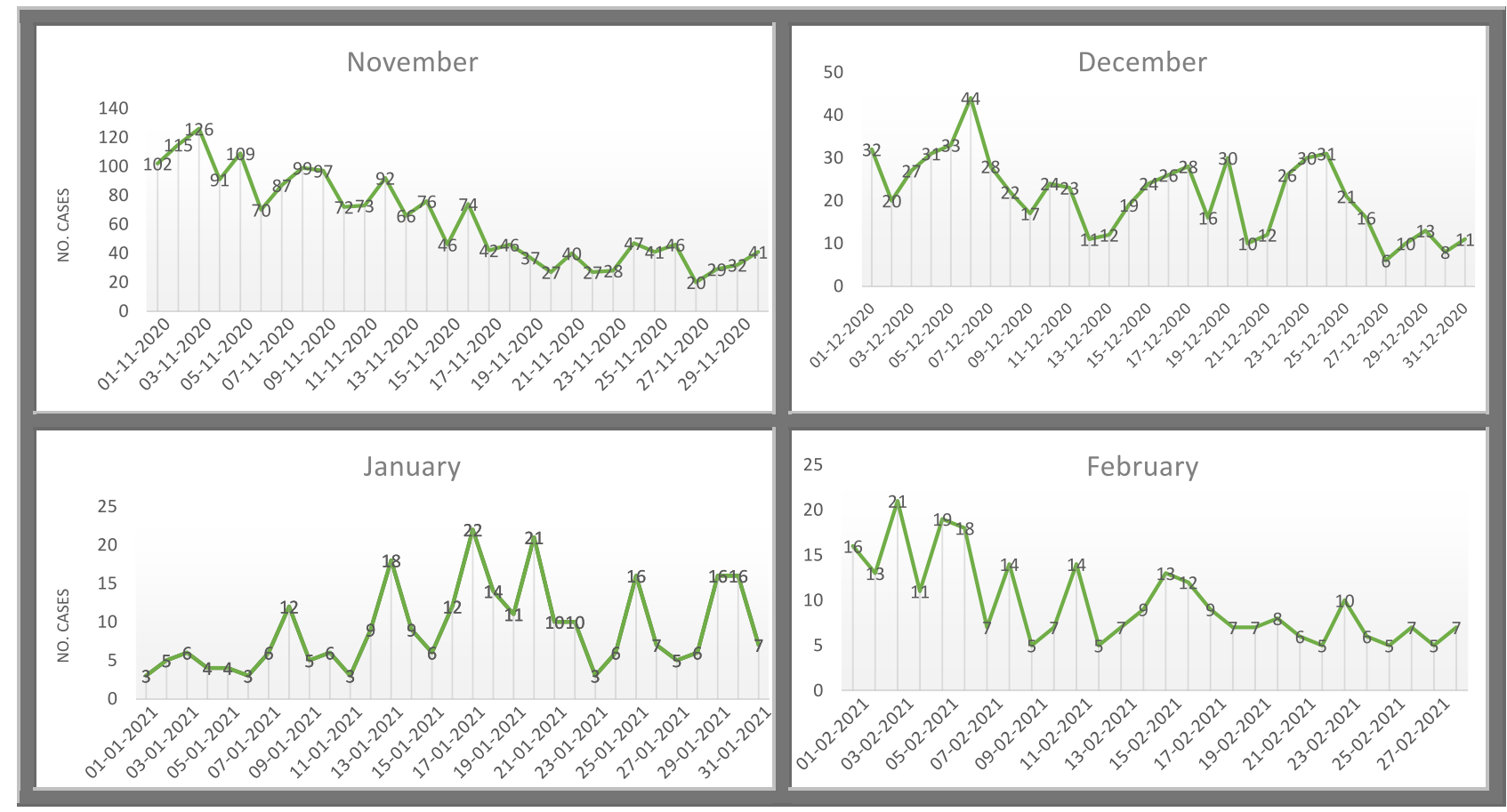

Figure 5 Epidemiological Situation of AI Madinah AI Mounawarah (Ist of November 2020-27th of February 202I).

premises pedestrians not using Tawakkalna, which follows robust contact tracing and tracks the health status of individuals. This limited the transmission of the virus in public areas.
Extensive health awareness campaigns were launched on all platforms, ranging from major social media sites to cellular communication through text messaging and official emergency numbers (937). Community leaders were 
Table 2 Epidemiological Features of COVID-19 Cases in Al Madinah Al Mounawarah

\begin{tabular}{|l|l|l|l|}
\hline Age & Years & Number & Percentage \\
\hline & $0-10$ & 608 & $6 \%$ \\
& $11-20$ & 1823 & $18 \%$ \\
& $21-30$ & 2634 & $26 \%$ \\
& $31-40$ & 2431 & $24 \%$ \\
& $4 I-50$ & 1418 & $14 \%$ \\
& $5 I-60$ & 810 & $8 \%$ \\
Gender & $6 I+$ & 405 & $4 \%$ \\
\hline \multirow{2}{*}{ Nationality } & Male & 5774 & $57 \%$ \\
& Female & 4355 & $43 \%$ \\
\hline Occupation & Saudi & 7192 & $71 \%$ \\
& Non-Saudi & 2937 & $29 \%$ \\
\hline Source of infection & Employee & $638 I$ & $63 \%$ \\
& Non-employee & 3748 & $37 \%$ \\
& Family Ist degree & 3748 & $37 \%$ \\
& Family 2nd degree & 608 & $6 \%$ \\
& Workplace & 1215 & $12 \%$ \\
& Household & 4558 & $45 \%$ \\
\hline
\end{tabular}

also involved through careful coordination to better reach targeted demographics in Al Madinah Al Munawwarah.

All mitigation measures were extensively implemented, and containment strategies were followed, as elaborated above.

\section{Epidemiological Situation After Implementation of Mitigation and Containment Strategies Measures}

On November 1, 2020, all mitigation measures and containment strategies were implemented widely and extensively. Table 3 shows the various digital platforms used during the implementation within each pillar of the response, such as Tawakkalna. The epidemic curve (Figure 4) depicts a notable decrease in the number of cases in Al Madinah Al Mounawarah after implementation, with the percentage of decline reaching $61 \%$, from 1900 in November to 70 in March (Figure 6). The strategy remains operational as of the date of publication of this paper and has been adopted nationwide so that a second COVID-19 wave, an apparent pattern in other countries, can be anticipated.

\section{Discussion}

The KSA was able to successfully contain the outbreak and prevent a second COVID-19 wave by effectively curbing the rising number of infections in real time using technological means by directly integrating digital tools in mitigation measures and containment methods. The Kingdom's overall strategy was to be comprehensive and precautionary by taking a proactive stance in facing this pandemic and applying all global recommendations to mitigate risk. This stance was further strengthened by the utilization of and investment in an existing strong digital infrastructure, which made it a powerful enabler for every mitigation and containment step.

Similar results were found in other countries according to a paper published in lancet digital health that listed the countries according to the use of the five pillars: tracking, screening for infection, contact tracing, quarantine and self-isolation, clinical management, china Singapore Taiwan Germany Sweden Australia USA and other countries Have used IT in its implementation of containment strategies, regardless of its possible breach on private information. This paper concluded that The use of digital technology in the operation and application of public health measures is one of several steps taken by countries that avoided a second wave and lowered their mortality rates. $^{31}$

Another review titled Digital technology use during COVID-19 pandemic: A rapid review concluded that along with other benefits of digital technology used during this pandemic, these technologies has significantly offered protection and support for public health. ${ }^{13}$

Due to the Kingdom's highly regarded digital infrastructure - which was adopted by and assimilated into the healthcare sector, rendering the use of past traditional processes impractical - the swift application of innovative and advanced technology in fighting the pandemic was in line with the country's vision and modern standards of healthcare. The mass digitization of foundational health services aligned with the basic principles of healthcare information technology, which encompassed a broad range of tools - extending from everyday services to largescale digitization of health records. Furthermore, in the area of infection screening, artificial intelligence (AI), thermal cameras, and various smartphone applications were utilized in China, Taiwan, Singapore, and Iceland. Although the effectiveness of such measures is inconclusive, they failed to detect asymptomatic individuals. Moreover, the study found that Germany, Singapore, and South Korea used digital bracelets and GPS tracking through digital devices in the area of contact tracing. Notwithstanding the possible breach of privacy, this 


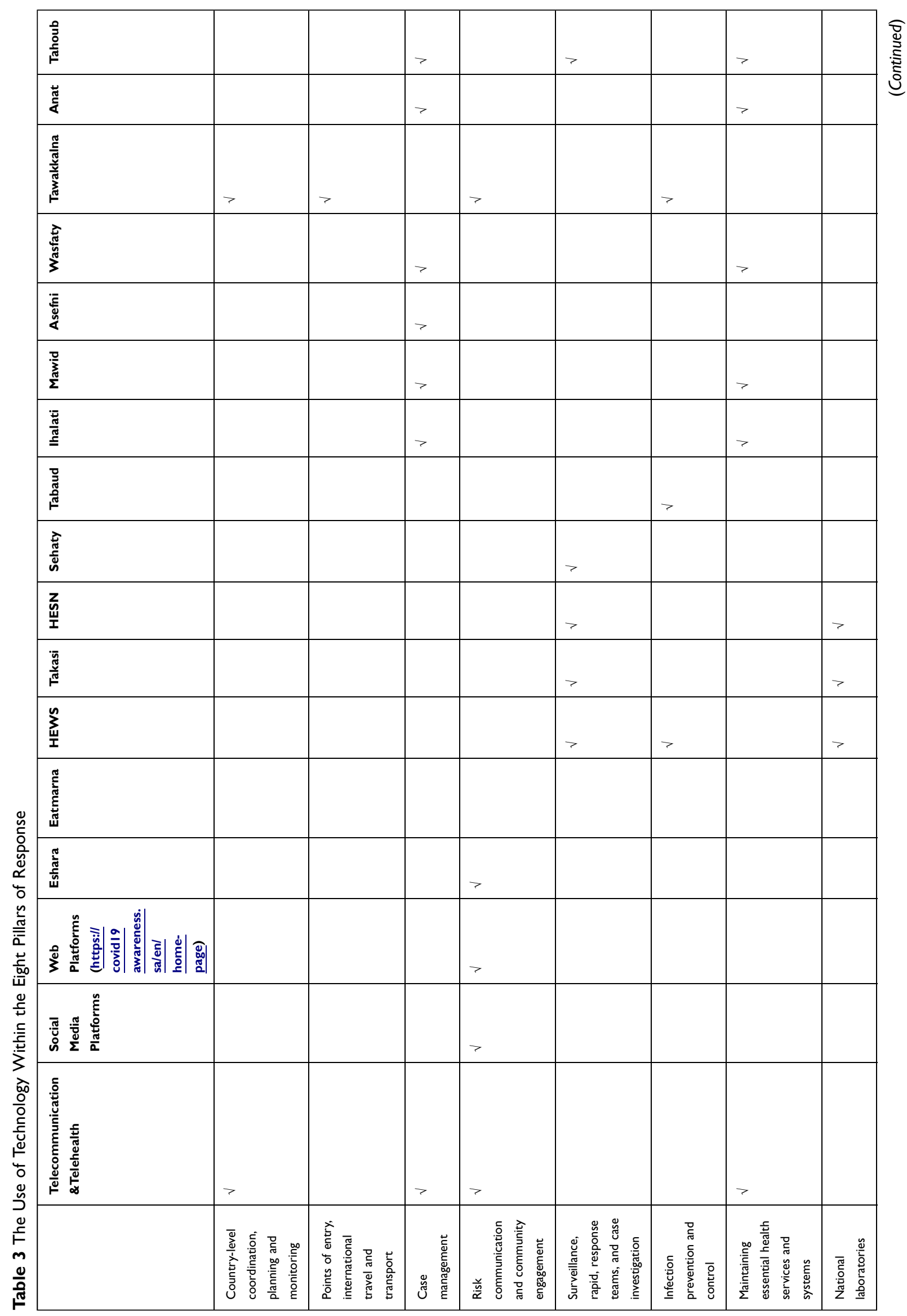




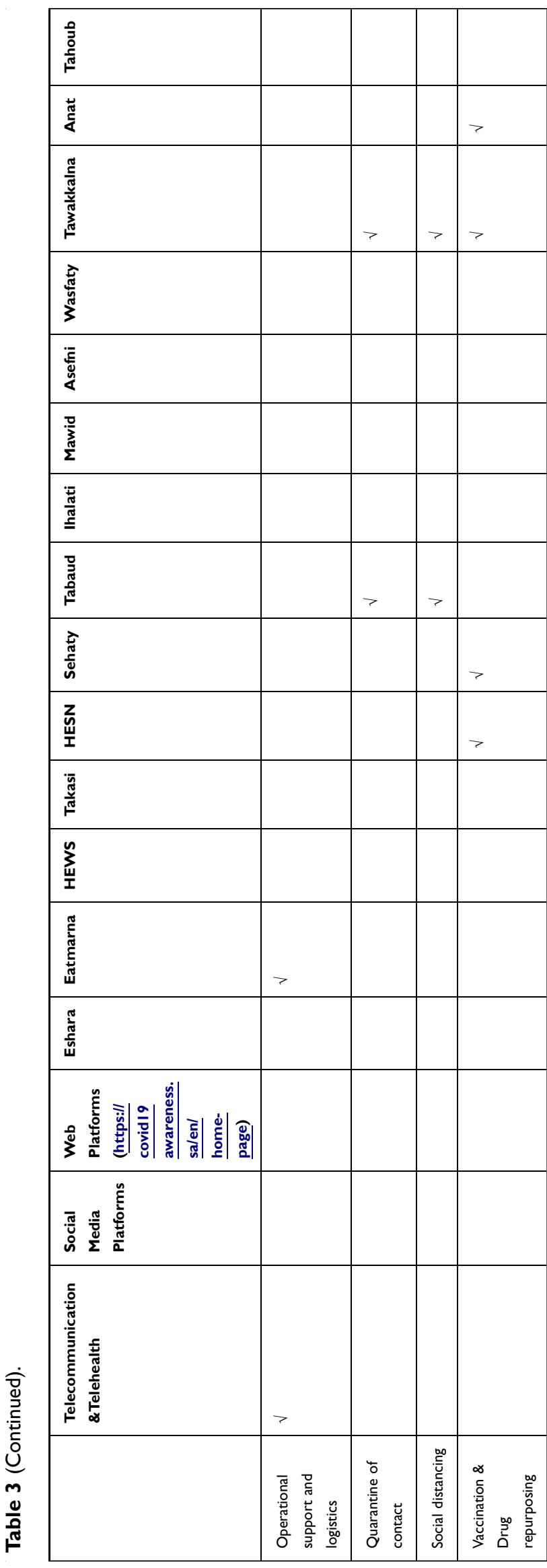

method may prove to be beneficial in tracking and investigating infected persons and preventing further spread through unknown contact by actively warning healthy individuals and enabling the quarantining of positive individuals. China, Australia, Iceland, and South Korea used similar methods in the area of quarantine and self-isolation as well. Lastly, in the area of clinical management, China, Australia, Canada, Ireland, and the USA utilized various digital tools, including AI, for medical diagnosis, telemedicine, and machine learning. These tools enabled following development of patients' health status and predict future trends in the epidemic curve. ${ }^{32-34}$

In this paper, we have showcased the KSA's experience with the use of digital technology during the COVID-19 pandemic. This experience proved that the KSA was one of the first countries to fully integrate technology during every stage of the pandemic and incorporate digital tools in all mitigation measures and containment policies. This fullscale incorporation was further shown to be comprehensively integrated with the national eight pillars of response as represented in Table 3, making the function vital to the pillars' implementation. Additionally, the effective use of technology was apparent in Al Madinah Al Mounawarah's experience in curbing its rising number of cases. This was further displayed in the epidemiological progress over time, where a notable decrease in cases was recorded after the implementation of the digital tool Tawakkalna, which was connected to all digital health platforms. Tawakkalna played a major role in decreasing the number of new active daily cases after its launch in $\mathrm{Al}$ Madinah $\mathrm{Al}$ Munawwarah, beginning in November 2020. The spread was limited due to users being able to view their risk profile and their exposure to possibly positive individuals and avoid areas with a high number of reported cases. Civilians were further prohibited from visiting mass gathering areas such as shopping centers, governmental offices, and mosques without the use of Tawakkalna.

\section{Conclusion and Recommendations}

The use of the Tawakkalna application was proven to be a successful method in fighting the COVID-19 pandemic in the KSA. This vital and essential experience warrants a long-term comprehensive quantitative analysis to measure and document its impact on today's events and leverage it in drawing best practices alongside lessons learned from other countries' experiences. The documented success in $\mathrm{Al}$ Madinah Al Mounawarah of infected persons being actively tracked, their contact with healthy individuals minimized, and their attendance at gatherings prevented was merely 


\section{Percent of Change in Cases}

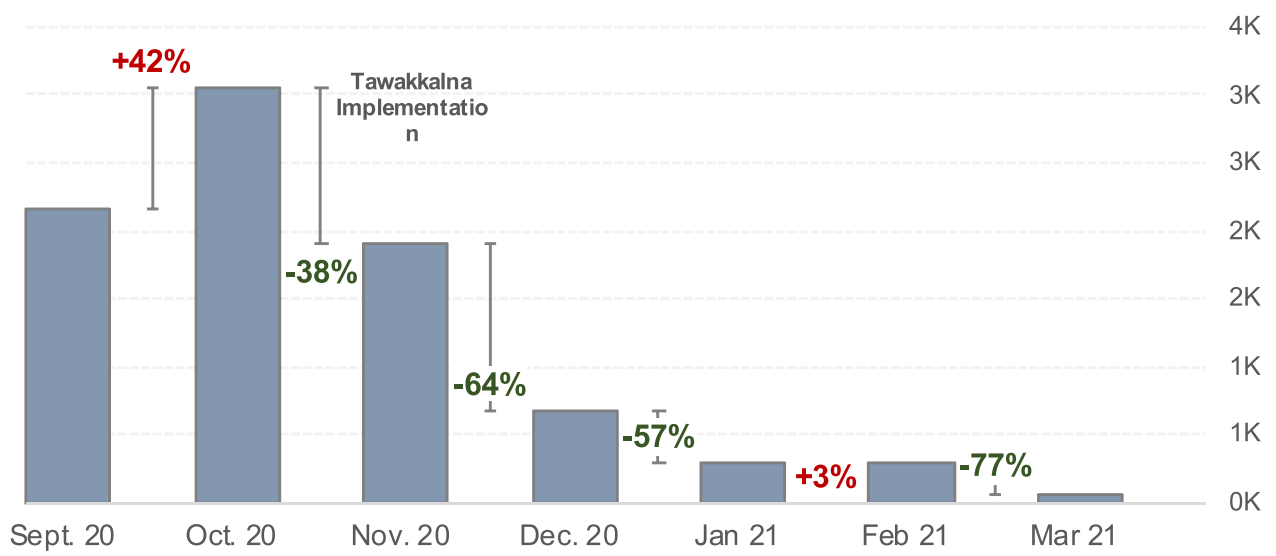

Figure 6 Percent of change in cases detected in Al Madinah Al Mounawarah from September 2020 until March 2021.

a step along the way to the implementation of the MoH's grand strategy. The use of different digital technologywhich offers a personalized profile displaying / the person's status (affected, vaccinated, no history of infection) - was and continues to play a crucial and effective role in pandemic containment in Saudi Arabia. This study, however, represents a unique experience: One application in only one city. Larger and more comprehensive studies are needed to assess the effect of all the different applications on all cities with a longer study period.

\section{Disclosure}

The authors report no conflicts of interest in this work.

\section{References}

1. Wang C, Horby PW, Hayden FG, Gao GF. A novel coronavirus outbreak of global health concern. Lancet. 2020;395(10223):470-473 doi:10.1016/S0140-6736(20)30185-9

2. Kucharski AJ, Russell TW, Diamond C, et al. Early dynamics of transmission and control of COVID-19: a mathematical modelling study. Lancet Infect Dis. 2020;3099(20):1-7. doi:10.1016/S14733099(20)30144-4

3. Li Q, Guan X, Wu P, et al. Early transmission dynamics in Wuhan, China, of novel coronavirus-infected pneumonia. New Engl J Med. 2020;382(13):1199-1207. doi:10.1056/NEJMoa2001316

4. World Health Organization (WHO). Novel Coronavirus (2019-nCoV) Situation Report - 121 February 2020. Novel Coronavirus (2019nCoV) Situation Report - 12; 2020:1-7.

5. Zhang X, Cai H, Hu J, et al. Epidemiological, clinical characteristics of cases of SARS-CoV-2 infection with abnormal imaging findings. Int $J$ Infect Dis. 2020;94:81-87. doi:10.1016/j.ijid.2020.03.040

6. Ghinai I, McPherson TD, Hunter JC, et al. First known person-toperson transmission of severe acute respiratory syndrome coronavirus 2 (SARS-CoV-2) in the USA. Lancet. 2020;395(10230):1137-1144. doi:10.1016/S0140-6736(20)30607-3

7. Bianconi A, Marcelli A, Campi G, Perali A. Efficiency of Covid-19 containment by measuring time dependent doubling time. arXiv. 2020;17(6):065006. doi:10.1088/1478-3975/abac51
8. Jackson J, Weiss M, Schwarzenberg A, Nelson R. Global economic effects of COVID-19. Congressional Res Service. 2020;20:78.

9. Alahmari AA, Khan AA, Elganainy A, et al. Epidemiological and clinical features of COVID-19 patients in Saudi Arabia. J Infect Public Health. 2021;14(4):437-443. doi:10.1016/j.jiph.2021.01.003

10. CCC - command and control center. Available from: https://www. moh.gov.sa/en/CCC/Pages/default.aspx. Accessed March 28, 2021.

11. Kingdom of Saudi Arabia ministry of health covid 19 command and control center CCC the national health emergency operation center NHEOC; 2020. Available from: https://covid19.moh.gov.sa/. Accessed September 1, 2021.

12. Golinelli D, Boetto E, Carullo G, Nuzzolese AG, Landini MP, Fantini MP. Adoption of digital technologies in health care during the COVID-19 pandemic: systematic review of early scientific literature. J Med Internet Res. 2020;22(11):e22280. doi:10.2196/22280

13. Vargo D, Zhu L, Benwell B, Yan Z. Digital technology use during COVID-19 pandemic: a rapid review. Human Behav Emerg Technol. 2021;3(1):13-24. doi:10.1002/hbe2.242

14. Almuzaini Y, Mushi A, Aburas A, et al. Risk communication effectiveness during COVID-19 pandemic among general population in Saudi Arabia. Risk Manag Healthc Policy. 2021;14:779-790. doi:10.2147/RMHP.S294885

15. About MOH portal - social media. Available from: https://www.moh. gov.sa/en/Portal/Pages/Socials.aspx. Accessed March 28, 2021.

16. MOH Publications. Media report on MOH's services on the occasion of ninth allegiance anniversary $1435 \mathrm{H}$. Available from: https://www. moh.gov.sa/en/Ministry/MediaCenter/Publications/Pages/ Publications-2014-04-20-001.aspx. Accessed March 28, 2021.

17. E-Services - (Tetamman) App. Available from: https://www.moh.gov. sa/en/eServices/Pages/Rest-assured.aspx. Accessed March 28, 2021.

18. Eshara. Available from: https://www.my.gov.sa/wps/portal/snp/pages/ eshara/!ut/p/z0/04_Sj9CPykssy0xPLMnMz0vMAfIjo8zi_ Q x d D T w M T Q z 9 _ U 3 c L A 0 C T Y 0 s D V y NLAzdDQz0g1Pz9AuyHRUBPWxoXQ!!/. Accessed March 28, 2021.

19. Mobile Applications. Ministry of Hajj and Umrah. Available from: www. haj.gov.sa/en/InternalPages/Details/10234. Accessed March 28, 2021.

20. WHO EMRO. Hajj health and safety boosted by new health early warning system actualités centre des médias. http://www.emro.who. $\mathrm{int} / \mathrm{fr} / \mathrm{media} /$ actualites/hajj-health-and-safety-boosted-by-new-healthearly-warning-system.html. Accessed March 28, 2021.

21. MOH Publications. Saudi Arabia's experience in health preparedness and response to COVID-19 pandemic. Available from: https://www. moh.gov.sa/en/Ministry/MediaCenter/Publications/Pages/ Publications-2020-10-27-001.aspx. Accessed March 28, 2021. 
22. What is HESN?. HESN portal. Available from: https://hesn.moh.gov. sa/webportal/what-is-hesn-. Accessed March 28, 2021.

23. Tabaud. Available from: https://tabaud.sdaia.gov.sa/IndexEn. Accessed March 28, 2021.

24. E-Services. (Mawid) Service. Available from: https://www.moh. gov.sa/en/eServices/Pages/cassystem.aspx. Accessed March 28, 2021.

25. MOH News. MoH: all the kingdom will be covered by telemedicine in two months. Available from: https://www.moh.gov.sa/en/Ministry/ MediaCenter/News/Pages/news-2018-03-06-006.aspx. Accessed March 28,2021

26. Saudi red crescent launches "Asefni" app to request emergency service Arab news. Available from: https://www.ara bnews.com $/$ node $/ 1306831 /$ saudi-arabia?page $=5$. Accessed March 28, 2021.

27. Alaqeel S, Abanmy NO. Counselling practices in community pharmacies in Riyadh, Saudi Arabia: a cross-sectional study. BMC Health Serv Res. 2015;15:557. doi:10.1186/s12913-015-1220-6

28. Sehaty. Available from: https://sehaty.sa/en/home. Accessed March 28, 2021.
29. MOH News. MOH confirms readiness of CCC, No new coronavirus cases reported in the kingdom. Available from: https://www.moh.gov. sa/en/Ministry/MediaCenter/News/Pages/News-2020-02-11-003. aspx. Accessed March 28, 2021.

30. Tawakkalna. Available from: https://ta.sdaia.gov.sa/en/index. Accessed March 28, 2021.

31. Whitelaw S, Mamas MA, Topol E, Spall HGCV. Applications of digital technology in COVID-19 pandemic planning and response. Lancet Digital Health. 2020;2(8):e435-e440. doi:10.1016/S25897500(20)30142-4

32. Ting DSW, Carin L, Dzau V, Wong TY. Digital technology and COVID-19. Nat Med. 2020;26(4):459-461. doi:10.1038/s41591-0200824-5

33. Garfin DR. Technology as a coping tool during the coronavirus disease 2019 (COVID-19) pandemic: implications and recommendations. Stress Health. 2020;36(4):555-559. doi:10.1002/smi.2975

34. Whitelaw S, Mamas MA, Topol E, Van Spall HGC. Applications of digital technology in COVID-19 pandemic planning and response. Lancet Digital Health. 2020;2(8):e435-e440. doi:10.1016/S25897500(20)30142-4
Risk Management and Healthcare Policy

\section{Publish your work in this journal}

Risk Management and Healthcare Policy is an international, peerreviewed, open access journal focusing on all aspects of public health, policy, and preventative measures to promote good health and improve morbidity and mortality in the population. The journal welcomes submitted papers covering original research, basic science, clinical \& epidemiological studies, reviews and evaluations,

\section{Dovepress}

guidelines, expert opinion and commentary, case reports and extended reports. The manuscript management system is completely online and includes a very quick and fair peer-review system, which is all easy to use. Visit http://www.dovepress.com/testimonials.php to read real quotes from published authors. 